\title{
Doctors in a hyperbaric medical unit: what is the hyperbaric exposure?
}

\author{
Richard Pougnet $^{1,2,3}$, Olivier Fenet ${ }^{4}$, Brice Loddé ${ }^{1,5}$, Guy Cochard ${ }^{1,4}$, \\ Anne Henckes ${ }^{1,4}$, Laurence Pougnet ${ }^{1,6}$ \\ ${ }^{1}$ Société Française de Médecine Maritime (SFMM), French Society of Maritime Medicine, Brest, France \\ ${ }^{2}$ Occupational Diseases Unit, University Hospital of Brest, France \\ ${ }^{3}$ Laboratoire d'Etudes et de Recherches en Sociologie (LABERS), EA 3149, Université de Bretagne Occidentale, Brest, France \\ ${ }^{4}$ Hyperbaric Medical Unit, University Hospital of Brest, France \\ ${ }^{5}$ Optimisation des Régulations Physiologiques (ORPHY), EA 4324, Université de Bretagne Occidentale, Brest, France \\ ${ }^{6}$ Military Hospital, HIA Clermont-Tonnerre, Brest, France
}

Work in hyperbaric medical units exposes to several occupational risks. Hyperbaric oxygen therapy can be done in pressure chambers with or without the presence of an attendant. This attendant, who can be a nurse, a doctor or a technician, may provide technical support during hyperbaric chamber sessions, such as mechanical ventilation, blood gas measurement etc. [1, 2]. These hyperbaric medical unit workers are exposed to many occupational risks related to hyperbaric conditions. So a recent review of the literature showed that the decompression illness (DCl) incidence ranged from 0 to 37 per 100,000 sessions in hyperbaric chambers (SHC). Despite this low incidence, at least 2 nurses died according to the literature [3].

Moreover, caregivers are exposed to other risks related to their occupation. A French retrospective study among these workers showed that $27 \%$ of the subjects had at least one occupational accident during the study period between 2005 and 2011. In this study, there were different kinds of occupational accidents. On 30 accidents reported, there were 3 blood exposures, and 4 accidents related to patient handling [4].

However, accidents mainly concerned paramedical staff in these studies, while in French hospitals, doctors represent 1 quarter of the workforce. Several hypotheses could explain why doctors had fewer accidents. For example, they may do less SHC, or they may not do the same types of $\mathrm{SHC}$, or they may report fewer accidents. This study aimed to better assess the hyperbaric exposure of physicians in a hyperbaric medical unit.

It was a retrospective study in our medical unit, including all SHC during 1 year. The SHC profiles (pressure and duration) and the indications of the session have been identified. During the study, 5 doctors and 15 non-doctors worked in the unit.

There were 665 SHC, of which 37 (6\%) were done by a doctor. Doctors did $30 \%$ of the SHC which were done to treat accidents of dive; they did $50 \%$ of SHC which were done to treat CO intoxication, and $40 \%$ of SHC which were done to treat gas gangrenous. Medical presence was conditioned by the severity of the patient's condition. The 29 SHC for a major medical emergency were done by a doctor: $24 \mathrm{SHC}$ for $\mathrm{DCl}$ and $5 \mathrm{SHC}$ for other indications. So, doctors did SHC mainly for medical emergencies (Fig. 1). Consequently, the doctors were doing the longest sessions or those with the highest atmospheric pressures (Fig. 2).

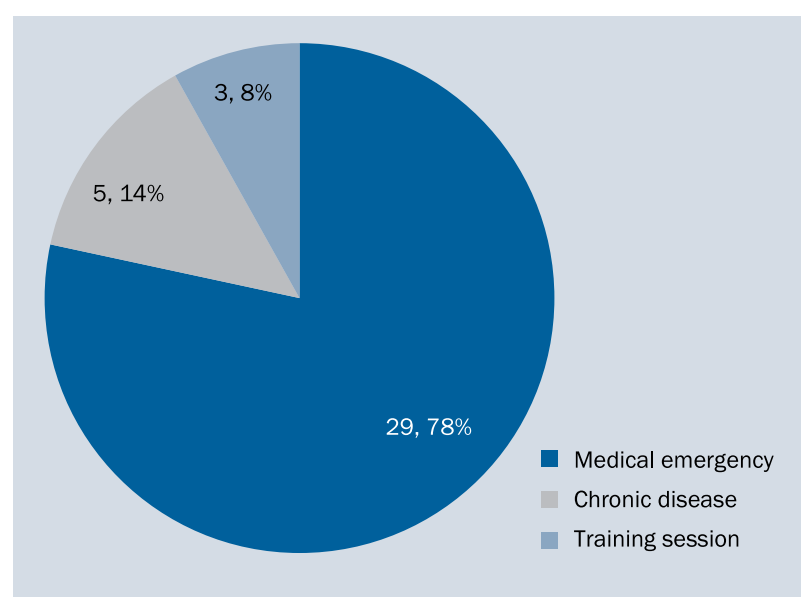

Figure 1. Medical indications of the sessions in hyperbaric chamber practiced by doctors 


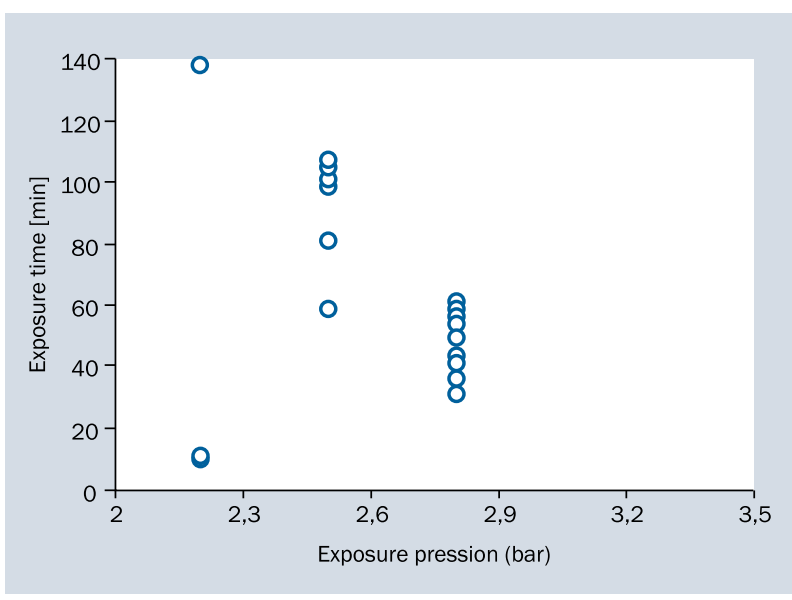

Figure 2. Profile of sessions in hyperbaric chamber practiced by doctors

This study showed that doctors practiced less SHC than paramedics. This could explain why there are fewer accidents among doctors. Yet, doctors made the most technicalIy difficult sessions, both in terms of medical care and SHC profile. Doctors did longer or higher-pressure sessions. So, the risk of accident is not negligible for doctors. Difficult care might make it more likely to cause care-related accidents, such as body fluid exposure. The SHC profile can expose them to accidents related to hyperbaric conditions, such as otitis or DCl. It is therefore important to continue prevention for this population [5].

\section{REFERENCES}

1. Moon RE, Hart BB. Operational use and patient monitoring in a multiplace hyperbaric chamber. Respir Care Clin N Am. 1999; 5(1): 21-49, indexed in Pubmed: 10205812.

2. Pougnet R, Pougnet L, Lucas $D$, et al. Health effects of hyperbaric exposure on chamber attendants: a literature review. Int Marit Health. 2018; 69(1): 58-62, doi: 10.5603/IMH.2018.0009, indexed in Pubmed: 29611615.

3. Clarke R. Health care worker decompression sickness: incidence, risk and mitigation. Undersea Hyperb Med. 2017; 44(6): 509-519, indexed in Pubmed: 29281188.

4. Pougnet R, Henckes A, Pougnet L, et al. Occupational accidents among attendants inside hyperbaric chambers in France. Med Lav. 2015; 106(1): 17-22, indexed in Pubmed: 25607284.

5. Song M, Hoon SeJ, Shin TM. An anti-barotrauma system for preventing barotrauma during hyperbaric oxygen therapy. Undersea Hyperb Med. 2018; 45(1): 19-25, indexed in Pubmed: 29571228. 